\title{
Studies in man and cat of the significance of the $\mathrm{H}$ wave ${ }^{1}$
}

\author{
R. F. MAYER AND C. MAWDSLEY ${ }^{2}$ \\ From the Neurological Unit, Boston City Hospital, and the Department of Neurology, \\ Harvard Medical School
}

Since the original description of the $H$ wave by Hoffmann in 1918, numerous reports have appeared in the literature concerning its origin and significance (Magladery and McDougal, 1950; Magladery, Park, Porter, and Teasdall, 1952). This potential, which is recorded from muscle, has been reported to have the following characteristics in normal man. 1 It can be evoked by submaximal electric stimulation of the nerve supplying the muscle, for the afferent nerve fibres have a lower threshold than motor fibres (Hoffmann, 1918; Magladery and McDougal, 1950). 2 With stronger stimulation, motor fibres are activated and the response is obliterated (Hoffmann, 1918; Magladery and McDougal, 1950). 3 Its latency decreases as the site of stimulation is moved proximally (Hoffmann, 1918; Magladery and McDougal, 1950). 4 The potential can be facilitated by mild active contraction of the muscle (Magladery, Porter, Park, and Teasdall, 1951), passive stretching of the muscle (Angel and Hoffmann, 1963), and following tetanic stimulation (Hagbarth, 1962). 5 It can be inhibited by active contraction of the antagonists (Magladery et al., 1951), and passive shortening of the muscle (Angel and Hoffmann, 1963). From these characteristics it has been concluded that the $\mathrm{H}$ wave is the response of a monosynaptic reflex which is activated by stimulation of group I afferent fibres proximal to the muscle spindle. This reflex has been considered analogous to the muscle stretch reflex (tendon jerk).

However, some features of the response, such as the effect of the Jendrassik manoeuvre, are still disputed (Sommer, 1940; Buller and Dornhorst, 1957; Buller, 1957; Clare and Landau, 1964; Landau and Clare, 1964a; Gassel and Diamantopoulos, 1964b). Several other features of this potential are unusual for a monosynaptic response and have not

'This work was supported by a grant from the National Institute of Neurological Disease and Blindness, No. NB 02613-03, and the paper was presented in part at the eleventh annual meeting of the American Association of Electromyography and Electrodiagnosis, Boston, Massachusetts, on 23 August 1964.

'Rockefeller fellow. Present address, Manchester Royal Infirmary, Manchester. been adequately explained in the past. These are the following. The potential is most readily recorded from the surface of the calf muscles yet a potential with the above characteristics is not normally recorded from other muscles such as the small hand and foot muscles (Magladery and McDougal, 1950). Following electric stimulation with single shocks there is a prolonged period of depression of the response which persists over 20 seconds (Paillard, 1959; Mayer and Mawdsley, 1964), and the conduction velocity in the fastest afferent fibres which transmit the response is lower in patients with peripheral neuropathies than in normals (Mayer, 1963; Mawdsley and Mayer, 1964).

In recent studies the $\mathbf{H}$ wave has been used as a measure of monosynaptic reflex activity and hence motor neurone excitability (Magladery, Teasdall, Park, and Languth, 1952; Angel and Hoffmann, 1963; Landau and Clare, 1964b; Gassel and Diamantopoulos, 1964a). With this technique patients with spasticity and rigidity have been studied and compared with normals in an attempt to understand the mechanisms of altered motor function. However, in most of these studies, little attention has been paid to the great variability of the normal $\mathbf{H}$ wave and its specific characteristics.

Because of the unexplained features, the variability of the response and the continued use of the $H$ wave in the investigation of abnormal motor function, the parameters of the $\mathbf{H}$ wave should be clearly established. The present report describes a study of the $\mathbf{H}$ wave in man to define more completely its origin and significance. Because of the limitations of experimental studies in man, similar ones were performed in cats for comparison and possible physiological interpretation.

\section{MATERIALS AND METHODS}

HUMAN Twenty adult subjects without spinal cord or peripheral nerve dysfunction were studied as well as many patients with peripheral nerve abnormality (64 patients with diabetic neuropathy, 56 cases of alcoholic-nutri- 
tional neuropathy, 20 cases with focal neuropathies, and 20 patients with neuropathies from other causes). Patients with hemiplegia and paraplegia of varying causes were also studied.

The $\mathrm{H}$ wave was recorded using the surface technique described by Magladery and McDougal (1950). The sciatic nerve was stimulated in the popliteal fossa and $20 \mathrm{~cm}$. proximally in the posterior thigh (Fig. 1). A Grass S4) electric stimulator was used with bipolar and concentric needles as well as surface electrodes. The frequency of stimulation varied from 1 per 60 seconds to 450 per second. Intensity ( 0.5 to 150 volts) and duration $(0.05$ to $1 \mathrm{msec}$.) of stimulus were varied to study the minimal and maximal responses. Stimulating with a needle electrode was necessary to obtain maximal motor responses.

The $\mathbf{H}$ waves were recorded from the calf using surface electrodes. (In this report the $\mathrm{H}$ wave refers to the response recorded only in the calf muscles unless stated otherwise.) The usual point of recording was at the lower end of the gastrocnemius muscles in mid line, point B (Fig. 1) but recordings were obtained at many sites on the calf to determine the points of maximal amplitude. Potentials were also recorded from other muscles including the small foot and hand muscles following stimulation of their nerves. Concentric needles, bipolar concentric needles (inter-electrode distance of $1 \mathrm{~mm}$.), and multilead electrodes (Disa) have been used to record from individual muscles. The potentials were displayed on a cathode ray oscilloscope and photographed with the signal from a time mark generator.

The conduction velocity was determined in the fastest motor fibres to the triceps surae (medial and lateral gastrocnemius and soleus muscles). The tibial nerve was stimulated with supramaximal electric shocks in the popliteal fossa and $20 \mathrm{~cm}$. proximally using a needle electrode. The potentials were recorded with surface electrodes at point $\mathbf{B}$. The velocity was determined between the two points of stimulation (velocity = distance/ time). The speed of conduction was also determined in the fastest afferent fibres subserving the $H$ wave between these same points. The latency of the response from proximal stimulation was subtracted from the latency from distal stimulation and the velocity calculated using the above formula.

In two experiments the $\mathrm{H}$ wave was observed during ischaemia, which was produced by a cuff around the thigh inflated to a pressure of 250 to $300 \mathrm{~mm}$. $\mathrm{Hg}$, as described by Magladery, McDougal, and Stoll (1950). The amplitude and latency of the $H$ wave were recorded at intervals during the period of ischaemia until the response disappeared. The evoked nerve and muscle action potentials distal to the cuff were also recorded. The intramuscular temperature of the calf was measured with a needle thermister throughout the period of ischaemia and it remained normal $\left(34\right.$ to $36^{\circ} \mathrm{C}$.).

In eight cases, the $\mathbf{H}$ wave was studied in patients during spinal anaesthesia for local surgery. Anaesthesia was produced by injecting a hyperbaric solution of tetracaine (varying from 6 to $14 \mathrm{mg}$. with neosynephrine in different cases) intrathecally. The potentials were recorded from calf muscles and small plantar and dorsal foot muscles during injection of the anaesthestic and at varying intervals thereafter until complete clinical recovery. Sensory, motor, and reflex functions were tested during this period. In one case the $H$ wave was recorded during general anaesthesia (Fluothane).

CATS Twenty experiments were performed in adult cats. The animals were anaesthetized with pentobarbital $\Omega$ sodium (30 to $40 \mathrm{mg}$. $/ \mathrm{kg}$.) in order to prepare the extremities. At the time of recording, the animals had active corneal and pinna reflexes and in most experiments could : be aroused. Surface and direct stimulation of the sciatic $\overrightarrow{\vec{S}}$ nerve in the popliteal fossa and thigh was performed 7 with electric shocks of varying strengths $(0 \cdot 1 \mathrm{~V}$ to $150 \mathrm{~V})$ and rates ( 1 per minute to 450 per second). Recordings of $\frac{\bar{\sigma}}{\bar{\omega}}$ the potentials were made with surface electrodes which $\frac{\vec{D}}{\overrightarrow{0}}$ consisted of E.E.G. pin electrodes. The active lead was $\unrhd$ placed in the subcutaneous tissue over the calf muscles and the inactive lead over the Achilles tendon. Surface recordings from plantar foot muscles were also made. Bipolar needles (insulated to the tip), multilead electrodes $\overrightarrow{\overrightarrow{\vec{\omega}}}$ (Disa), and concentric needles were used for recording $\omega$ in many leg muscles. Potentials were observed with reference to threshold, latency, amplitude, and site of origin. $\frac{7}{0}$ The amplitude of the potentials was recorded following in tetanic electric stimulation, 450 per second for 10 to 20 seconds.

In 10 experiments, the potentials were studied follow ing acute (two to six hours) or chronic (four to six days $\overrightarrow{0}$ spinalization (the spinal cord was transected in the mide thoracic region). The sciatic nerve or dorsal roots (\$ and L7) were sectioned proximal to the site of stimulas tion at the end of the experiments. This was done order to establish the relationship of the potential to. $\overrightarrow{0}$ proximal conduction.

\section{RESULTS IN MAN}

THRESHOLD In all normal cases the $H$ wave was recorded from the surface of the calf muscles following submaximal stimulation of the tibial nerve in the $\varrho$ popliteal fossa. With surface stimulation of the tibial $\overrightarrow{\overrightarrow{0}}$ nerve at the above site, the $H$ wave was usually 3 evoked with a smaller stimulus than required for motor fibres although a few motor fibres were usually stimulated as well. With needle stimulation of the tibial nerve in the popliteal fossa, the $\mathbf{H}$ wave had the lowest threshold with the needle posterior to the nerve while the $\mathbf{M}$ wave (direct motor response) had the lowest threshold with the stimulus lateral and $\delta$ anterior to the nerve. Therefore the relative thresholds of the $H$ and $M$ waves varied with the positions $ᄋ$ of the stimulating electrode and the nerve. This suggests that in the tibial nerve in the popliteal fossa the large afferent fibres from the calf muscles lie more superficially than the large efferents.

CONDUCTION VELOCITY It is well known that the lowest threshold fibres are usually the largest $\sigma$

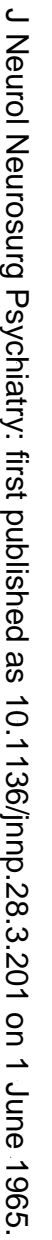


fibres and these fibres should have rapid conduction velocities. The mean velocity of the fastest motor fibres in the tibial nerve to the triceps surae was 81.5 metres per second ( 80 to 86 ). In the same segment of tibial nerve in the thigh, the mean rate of the fastest afferent fibres of the $\mathrm{H}$ reflex, measured as described under methods, was 82.6 metres per second (80 to 84 ).

Although these values differ from those reported in a recent study (Gassel and Trojaborg, 1964), they agree with the results of histological studies of nerve fibre size in man (Rexed, 1944) and cat (Eccles and Sherrington, 1930; Rexed and Therman, 1948; Lloyd and Chang, 1948). The diameters of the largest motor and sensory fibres in the tibial nerves are approximately the same and the maximum peaks of these large fibres are $13-15 \mu$ (osmic acid stain). Using the conversion factor of Hursh (1939) $(K=6)$, fibres this size would have conduction velocities ( 78 to 90 metres per second) in the range we determined. Although this factor $(\mathrm{K}=6)$ has been determined for cat peripheral nerve, it probably is applicable to human peripheral nerve since the conduction velocity in the fastest sensory fibres in the human median nerve at the wrist, 70 to 70 metres per second (Mayer, 1963), is approximately six times the diameter $(10-11 \mu)$ of the largest myelinated fibres in this nerve (Ranson, Droegemueller, Davenport and Fisher, 1934).

In normal young adults the mean latency of the $\mathrm{H}$ wave recorded at point $\mathrm{B}$ (Fig. 1) was $29 \mathrm{msec}$. ( 26 to $32 \mathrm{msec}$.). It was prolonged over the age of 50 and the mean latency was $32 \mathrm{msec}$. (30 to $34 \mathrm{msec}$.). In peripheral neuropathies the conduction time was prolonged and it varied from 34 to 41 metres per second. In these cases, the velocity of the afferent fibres in the tibial nerve in the thigh was 50 to 60 metres per second. When the latency was increased ( 36 to $40 \mathrm{msec}$.), the threshold of the $\mathrm{H}$ wave was raised and the amplitude decreased. In patients who did not have ankle jerks, secondary to a peripheral neuropathy, no $\mathrm{H}$ waves could be recorded.

AMPLITUDE The amplitude of the $H$ wave was usually the greatest (peak to peak measurement, 3 to $7 \mathrm{mv}$.) when recorded at the distal edge of the gastrocnemius muscles using surface electrodes. At this point (B, see Fig. 1), approximately 15 to $20 \mathrm{~cm}$. distal to the mid-popliteal point, the $\mathrm{H}$ wave appeared at a lower threshold than the $M$ wave and was usually larger in proportion to the $M$ wave than if recorded from over the bellies of the gastrocnemius muscles. The $\mathrm{H}$ wave was usually triphasic in shape and had a large negative (upward) component. The potential, which was recorded closer to the Achilles tendon (point A, Fig. 1), had a large initial

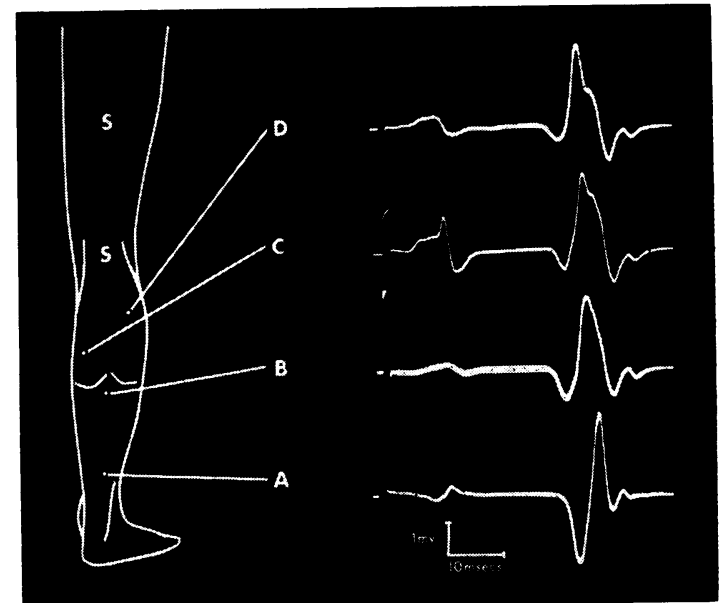

FIJ. 1. Points of stimulation $(S)$ of the tibial nerve and sites of recording ( $A$, soleus, $B$, junction gastrocnemius and soleus, $C$, medial gastrocnemius, and $D$, lateral gastrocnemius) are shown. Surface recordings of maximal $H$ waves appear adjacent to the site of recording. The stimulus artifact appears at left of tracings. The initial small deflection represents the direct motor response ( $M$ wave) and the later large deflection is the $H$ wave. Note that the $H$ wave at $A$ occurs later than at $B-D$. Negative polarity is upward.

positive phase and its negative component was usually smaller than that recorded at other points over the calf. The latency of the reflex recorded at this point was 1.5 to $2 \mathrm{msec}$. greater than that recorded in the mid calf. The maximal $\mathrm{H}$ wave in all experiments required a stimulus that evoked motor fibres as well but was never maximum for motor fibres. The intensity of this stimulus varied depending on the type and position of the stimulating electrode. A greater intensity was needed with surface than with needle electrodes. A smaller stimulus was required when the duration of the shock was long $(1 \mathrm{msec}$.). Increasing this stimulus produced a larger motor response while the $\mathrm{H}$ wave decreased in amplitude until it disappeared.

The amplitude of the $\mathrm{H}$ wave recorded with surface electrodes was extremely variable. Not only did the amplitude depend on the position of recording and strength of the stimulus but also on the frequency of the stimulus. Stimuli at intervals of 1, 10, or even 20 seconds produced $\mathrm{H}$ waves which varied in amplitude (Fig. 2). Stimuli at frequencies of 5 to 6 per second could obliterate the $\mathrm{H}$ wave without alteration of the $M$ response. There was little alteration in the amplitude of the response evoked at 30 -second intervals. Therefore, this rate of stimulation was used throughout the study. 


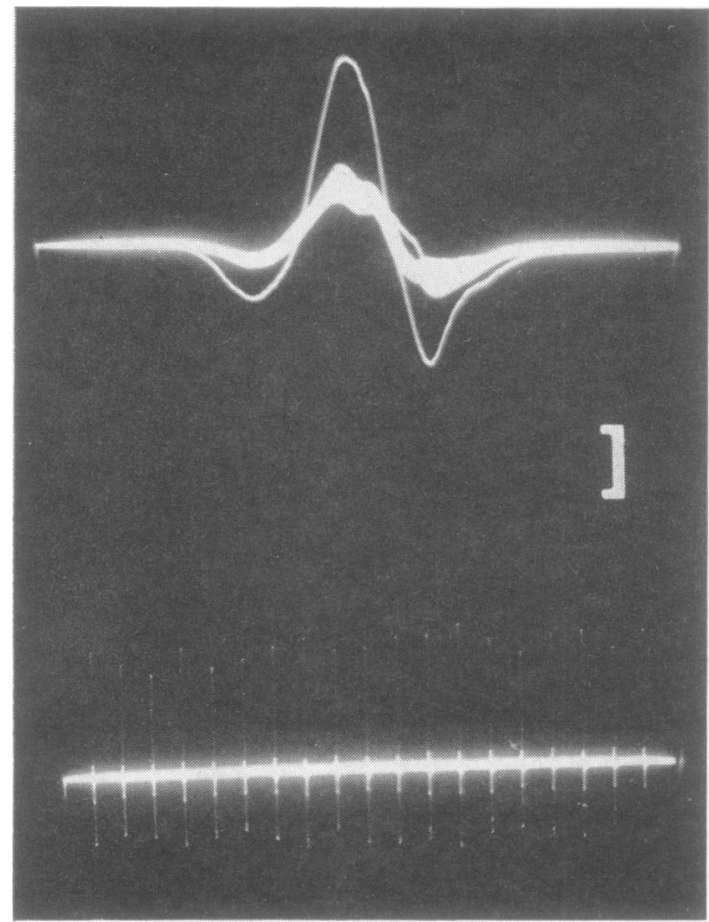

FIG. 2. Surface recordings of $\boldsymbol{H}$ waves following stimulation, one per second. In the upper tracing the potentials are superimposed; the largest response represents the initial one. In the lower tracing the potentials are recorded serially several seconds after the initial response. Amplitude marker equals $1 \mathrm{mv}$.

SITE OF ORIGIN An $H$ wave was recorded with surface electrodes from any point on the calf. This surface response represents a compound potential which could originate at some distance from the recording site. Therefore, concentric needle electrodes were used to analyse the $\mathrm{H}$ waves in the lateral and medial gastrocnemius and soleus muscles. An attempt was made to stimulate the nerve to the individual muscles using a small bipolar stimulating needle. In 10 experiments the nerve to the medial gastrocnemius was stimulated alone. In four of these cases an $\mathbf{H}$ wave was recorded in the medial gastrocnemius muscle at complete rest; facilitation produced by active contraction of the muscle was necessary to record it in an additional two cases. In four other experiments an $\mathbf{H}$ wave was not observed even with facilitation. During these experiments a large $H$ wave was recorded with surface electrodes over the muscle and no activity was recorded in the lateral gastrocnemius or soleus. Thus an $\mathbf{H}$ wave could be recorded in the medial gastrocnemius muscle alone but it was small in amplitude and difficult to locate (Fig. 3).

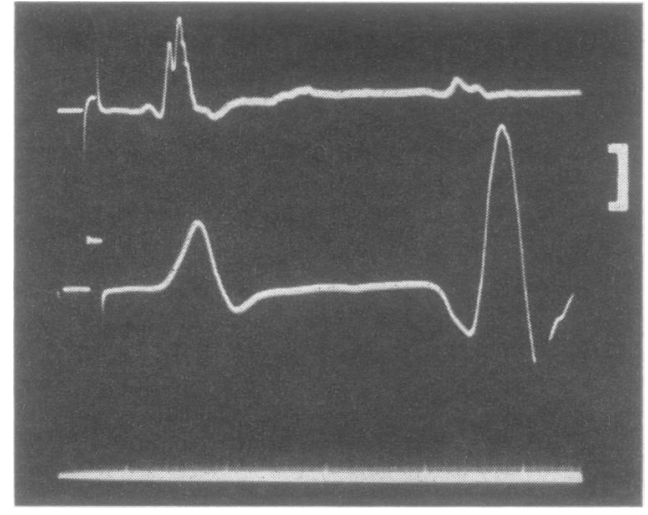

FIG. 3. Recordings of maximal $H$ waves in the medial gastrocnemius muscle with a concentric needle electrode $\overrightarrow{0}$ (upper) and from the surface (lower). Amplitude marker $\rightarrow$ equals $1 \mathrm{mv}$. and large time intervals are $5 \mathrm{msec}$.

The nerves to the lateral gastrocnemius and soleus muscles could not be stimulated individually but only together. An $\mathrm{H}$ wave could be recorded in the lateral gastrocnemius. It was usually small in ample tude but this was increased by mild active contra结 tion of the muscle. At the same time an $\mathrm{H}$ wave was also recorded in the soleus muscle but not in the medial gastrocnemius muscle. The potential in the soleus was small and the latency of the respon recorded at this point was 1.5 to $2 \mathrm{msec}$. greater tha⿳⺈. that recorded in the gastrocnemius muscles.

The $\mathbf{H}$ wave was more easily recorded in muscles with concentric needles during surface stimulation of the tibial nerve (Fig. 4). It was possible to obtain a large $H$ wave in the medial gastrocnemius muscle with only a minimal response in the soleus when the $\mathbb{D}$ tibial nerve was stimulated medially. A large po- $\underset{2}{\longrightarrow}$ tential could also be recorded in the soleus with a minimal response in the medial gastrocnemius when the nerve was stimulated laterally. These potentials which had different latencies also had different shapes; the wave in the medial gastrocnemius was triphasic while the potential in the soleus had a larger? initial positive deflection. This is probably due to the $\frac{5}{3}$ fact that the recordings were made in a volume conductor and the recording electrodes distally over the $\frac{0}{3}$ soleus were farther from the source of current than those over the gastrocnemius. These potentials were 음 similar to but smaller than those recorded on the surface of the calf. The potentials were facilitated and inhibited in the same way as those recorded N with surface electrodes but were more difficult to locate and study. Although similar potentials were $O$ not observed in other muscles, in one case a small $\tilde{\omega}$ late potential which appeared like an $\mathbf{H}$ wave was 


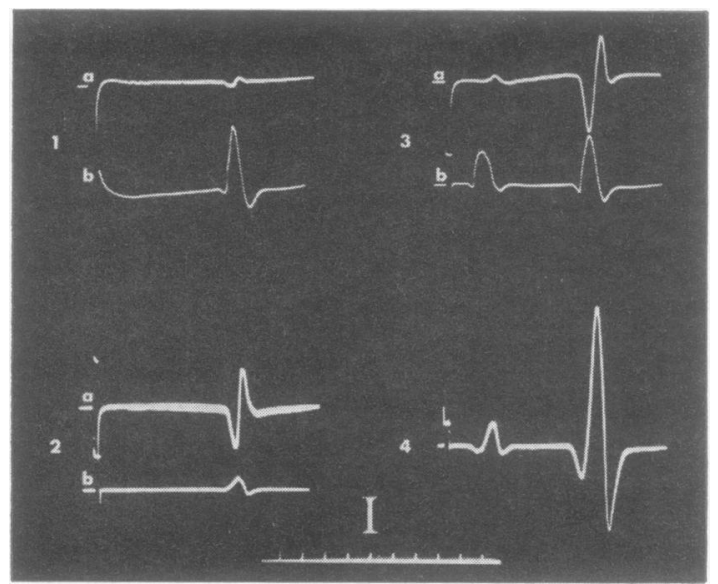

FIG. 4. Concentric needle recordings of $H$ waves in soleus (a) and medial gastrocnemius (b) following surface stimulation of the tibial nerve at 1, medial 2, lateral, and 3, mid portion of popliteal fossa; 4, surface recording from calf. Amplitude marker equals $1 \mathrm{mv}$. and time intervals are 5 msec.

recorded in the peroneus longus muscle following stimulation of the common peroneal nerve.

A late wave was recorded from the plantar foot muscles following stimulation of the tibial nerve in the popliteal fossa. This response has been called the F wave by Magladery and McDougal (1950). This potential was small (50 to $200 \mu \mathrm{V}$ ) and extremely variable. It required a stimulus which was maximum for motor fibres, was not obliterated by a supramaximal stimulus and was not evoked by every stimulus, even at one-minute intervals. The latency of the response decreased as the stimulus was moved proximally and varied with changes in the shape of the potential.

The conduction velocity in the fastest afferent fibres of this response varied over a wide range and was not consistent in the same individual. The rate in the segment of tibial nerve between ankle and popliteal fossa was approximately $\mathbf{4 0}$ to $\mathbf{5 0}$ metres per second. A similar response was recorded in the hand muscles. The velocity was $\mathbf{4 0}$ to 60 metres per second in the ulnar and median nerves between wrist and elbow. Because of the variability of the amplitude and latency of these potentials, more complete study was not possible.

In patients with hemiplegia a response, which had characteristics similar to $H$ waves, could be recorded from small hand muscles on the affected side. This potential was evoked by submaximal stimulation and inhibited by a maximal stimulus for motor fibres.
FACILITATION AND INHIBITION The amplitude of the $H$ wave could also be altered without any change in the intensity, duration, frequency, and site of stimulus or position of recording. An increase in the amplitude of a maximal response was most easily produced by mild active contraction of the muscle. Facilitation of the $\mathrm{H}$ wave was also observed with passive stretching of the muscle but this was not consistent since the same manoeuvre could produce inhibition, which was related to a greater force of stretching (Granit, 1955). The Jendrassik manoeuvre did not facilitate the maximal $\mathrm{H}$ response and the effect on submaximal $\mathrm{H}$ waves was variable; this appeared to be related to minimal active contraction of either the muscle or its antagonist. In our experiments, the Jendrassik manoeuvre was not an effective method of facilitating the $\mathrm{H}$ wave. Mark (1963) has shown that during the Jendrassik manoeuvre, muscle activity, recorded by electromyography, does occur in the calf muscles. Therefore, an increase in the amplitude of the $\mathrm{H}$ wave during this manoeuvre may be related to the active contraction of the muscles.

In several experiments, the amplitude of the $H$ wave was observed following tetanic stimulation (450 per second for 10 to 20 seconds) preceding the single test shocks. Mild facilitation could be produced although there usually was an increase in the direct motor response. This probably resulted from movement of either stimulating or recording electrodes during tetanic stimulation and thus the results were difficult to interpret.

A decrease in the potential was consistently produced by active contraction of the antagonist muscles. The amplitude could be reduced by passive relaxation of the muscle although this manoeuvre usually produced no change in the response. Reduction in amplitude of the $\mathrm{H}$ wave could be produced by strong active or passive movement of the ankle (flexion or extension). It appeared that the potential was more easily inhibited than facilitated.

Since the amplitude of the $\mathrm{H}$ wave is so readily altered by contraction of either the specific muscles from which the response is recorded, the synergists or antagonists, great care must be taken in monitoring muscle activity. This is particularly necessary if the amplitude of the response is to be evaluated during a variety of tests.

The facilitation of the $\mathrm{H}$ wave by passive stretching of the muscle or active contraction of the muscle is consistent with a monosynaptic reflex. The inhibition during passive relaxation of the muscle or active contraction of the antagonists is also observed in monosynaptic reflexes (Denny-Brown, 1928; Creed, Denny-Brown, Eccles, Liddell, and Sherrington, 1932; Lloyd, 1943c; Lloyd, 1946). However, the 
prominent inhibition during stronger flexion or extension is suggestive of polysynaptic connexions as well (Magladery et al., 1951).

EFFECT OF ISCHAEMIA During localized ischaemia of the sciatic nerve in the thigh produced by a cuff, the latency of the $\mathrm{H}$ wave increased 1.5 to $3 \mathrm{msec}$. without alteration of its amplitude or change in distal sensory or motor conduction. With prolonged ischaemia ( 20 to 30 minutes) the amplitude of the $\mathrm{H}$ wave decreased and the latency increased by a total of 5 to $6 \mathrm{msec}$. until the response disappeared. At this time distal motor conduction was normal, the evoked nerve potential diminished and the ankle jerk absent. The $\mathrm{H}$ wave returned rapidly after restoration of the blood supply but remained reduced in amplitude for 20 to 30 minutes. Paraesthesias in the foot persisted during this time.

EFFECT OF SPINAL ANAESTHESIA During spinal anaesthesia, the large $H$ wave disappeared within one minute after injection. Within this short period there was a rapid fall in amplitude and a slight increase in latency. A small $\mathrm{H}$ wave, which was evoked by maximal stimuli for motor fibres, persisted for three to six minutes. This potential had an amplitude of 70 to $120 \mu \mathrm{V}$ and its latency (34 to $38.5 \mathrm{msec}$.) was 4 to 5 milliseconds greater than that of the original $\mathrm{H}$ wave. During this period, superficial sensation and deep tendon reflexes in the legs were lost while motor power persisted.

There was no return of function in the legs until four to six hours after the onset of anaesthesia. Motor power and touch sensation returned first. No $\mathrm{H}$ waves or deep tendon reflexes were observed. However, at this time the $F$ wave could be recorded in the plantar and dorsal foot muscles. This potential returned at approximately the same time as the motor power in the foot and long before the return of the knee and ankle jerks.

Motor power and sensation returned to normal within 10 hours following the onset but the deep tendon reflexes and $\mathrm{H}$ waves did not return until 12 to 15 hours after the onset. The $\mathrm{H}$ wave at this time was small, its latency increased by 5 to 10 milliseconds and its threshold increased. The amplitude and latency of the potential slowly returned to normal within the next five hours.

The disappearance and return of the $H$ wave during spinal anaesthesia occurred at the same time as that of the ankle jerk. This suggests that both the $H$ wave and ankle jerk are subserved by fibres of the same size. These studies demonstrate that impulses which evoke the $\mathrm{H}$ wave are conducted proximally to the spinal cord.
RESULTS IN THE CAT

A potential with the characteristics of the human $\mathbf{H}$ wave could be recorded in cats (Figs. 5, 6). This potential was recorded from the surface of the calf and in the medial and lateral gastrocnemius and soleus muscles. It had the following characteristics:1 The wave was evoked by submaximal electric stimulation of the sciatic nerve and inhibited by a maximal stimulus for motor fibres. 2 It was inhibited by rapid stimulation (1 to 10 per second) and facilitated following tetanic stimulation. 3 The potential was obliterated by sectioning the sciatic nerve or dorsal roots (sacral 1) proximal to the site of stimulation. 4 With bipolar recording electrodes in the muscle, the potential was triphasic in shape; with surface recordings it was usually monophasic (negative polarity), and 5, its latency was 6.5 to 7.5 msec.

However, this potential was recorded in only one experiment performed in a normal cat anaesthetized with pentobarbital. Since the amplitude of the $\mathbf{H}$ wave in man was depressed during general anaesthesia (Fluothane) and pentobarbital can depress reflex activity (Brooks and Eccles, 1947), recordings were then made in spinal animals. In the acute state (two to six hours) $\mathrm{H}$ waves could be recorded in only two of four experiments. In the chronic state (four to six days) an $\mathbf{H}$ wave was recorded in all six experiments in spite of pentobarbital anaesthesia. Therefore, in cats, facilitation produced by some degree of recovery from spinal shock was necessary for the recording of the $\mathrm{H}$ wave during pentobarbital anaesthesia.

In the chronic spinalized cat, $\mathrm{H}$ waves could easily be recorded from the surface of the calf muscles. Although potentials were recorded in individual muscles, more care and time was required in placement of the electrodes. The characteristics of the potentials and the ease of recording were the same in gastrocnemius and soleus muscles. In these muscles the response was evoked from either surface or direct stimulation of the tibial nerve in the thigh. With surface or direct stimulation of the posterior aspect of the nerve, the $\mathrm{H}$ wave appeared with the lower stimulus intensity. With direct stimulation of the anterior aspect of the nerve the direct motor response appeared initially.

$H$ waves could also be recorded in other muscles of the leg (such as the extensor digitorum longus) and in the small plantar foot muscles. The latency of this latter potential was $8.5 \mathrm{msec}$. This response was obliterated by cutting the first sacral dorsal root.

In non-spinalized animals, a different late wave was recorded from the surface of the calf following surface stimulation of the tibial nerve in the thigh 


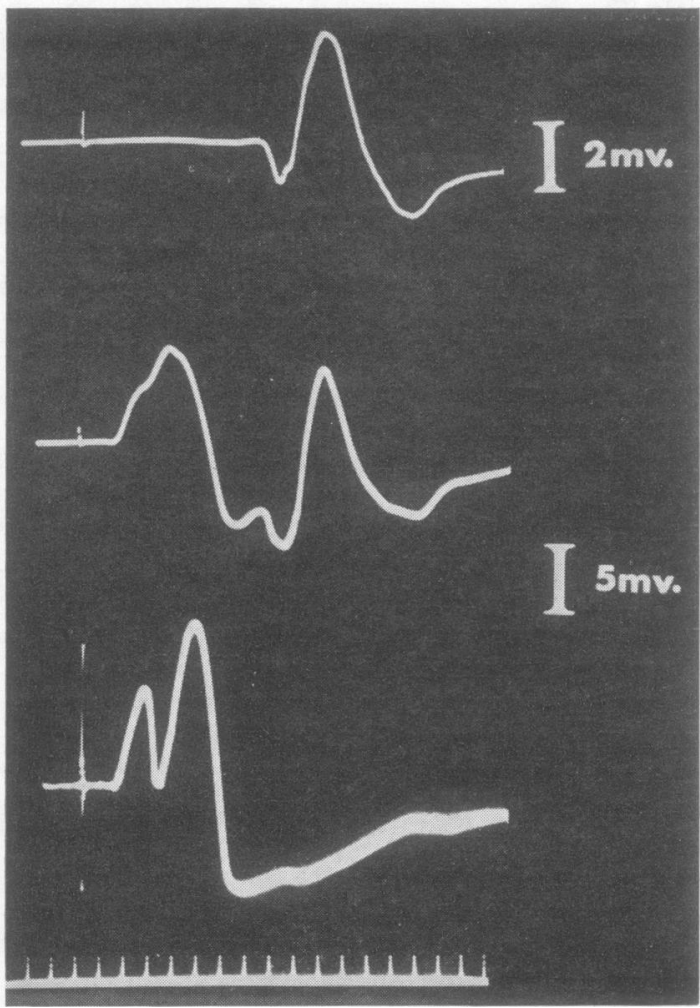

FIG. 5. Recordings of the $H$ wave in the lateral gastrocnemius muscle of an acutely spinalized cat; (upper) submaximal stimulation of the tibial nerve in the popliteal fossa; (middle) increase in stimulus; and (lower) maximal stimulus for motor response. Note that the $H$ wave is obliterated by the maximal stimulus. Time intervals equal 1 msec.

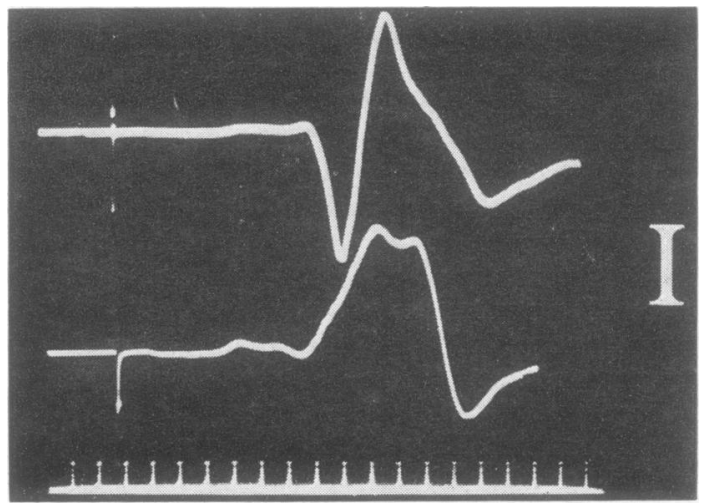

FIG. 6. Recordings of the $H$ wave in the lateral gastrocnemius muscle (upper tracing) and from the surface of the calf (lower tracing) in the same animals as in Figure 5. Amplitude marker equals $2 \mathrm{mv}$. and time intervals are 1 msec.
(Fig. 7). This potential had the following characteristics: 1 It was evoked by a submaximal electric stimulus and inhibited by a maximal stimulus for motor fibres. 2 It was inhibited by rapid stimulation ( 1 to 30 per second) and faciliated following tetanic stimulation. 3 This potential was not obliterated by sectioning the sciatic nerve proximal to the site of stimulation. 4 The wave was usually monophasic (negative polarity) and its latency varied from 8 to 11 milliseconds.

Since this potential persisted following proximal sciatic nerve section, it cannot be reflex in nature like the $\mathrm{H}$ wave. It did not depend on conduction in the peroneal, hamstring, sural, or femoral nerves. The wave was recorded with surface electrodes only and not with concentric needles in the triceps surae. Although its exact origin was not determined it probably represents a motor response evoked at some distance from the recording electrodes and recorded late as a result of slow extraneural conduction.

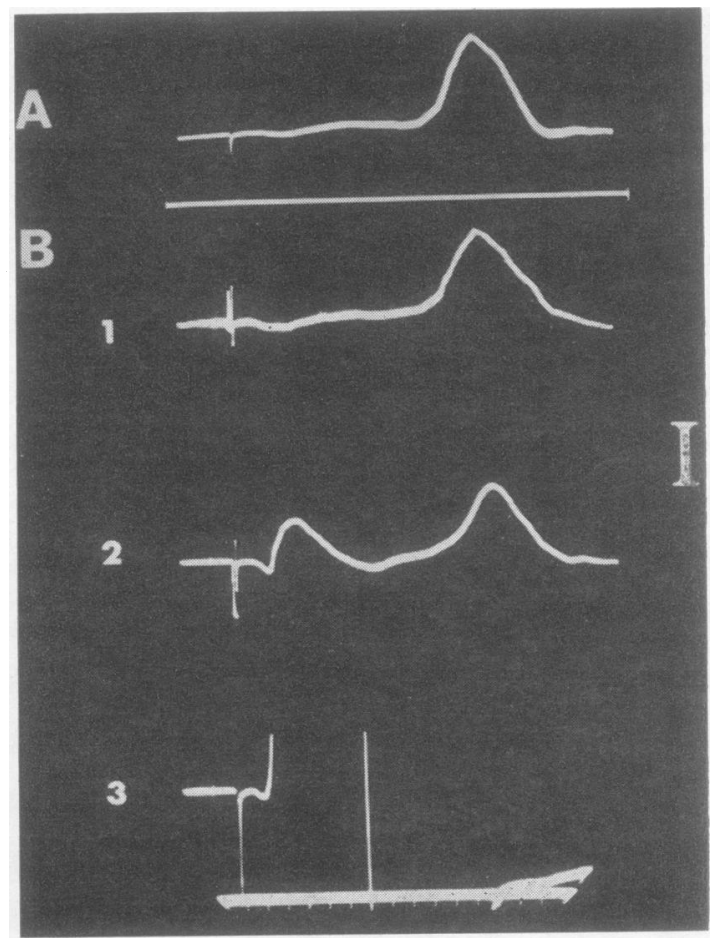

FIG. 7. Recordings of the late wave from the surface of the calf in an anaesthetized cat following stimulation of the tibial nerve in the thigh $(A)$ before sciatic nerve section and $(B)$ following sciatic nerve section. Stimulus strength was increased from submaximum $(1,2)$ to maximum for motor fibres (3). This response was the same before sciatic nerve section. Amplitude marker equals $0.5 \mathrm{mv}$. and time intervals are 1 msec. 


\section{DISCUSSION}

The $\mathrm{H}$ wave recorded from calf muscles truly represents a reflex response which is closely related to the Achilles tendon reflex. This response is blocked at the same time as the ankle jerk by ischaemia of the sciatic nerve in the thigh or spinal anaesthesia and therefore is dependent on proximal conduction. $\mathbf{H}$ waves are similar in man and cat. Since in the latter they are obliterated by dorsal root section and represent a true reflex, the response in man can be interpreted in the same way. Magladery et al. (1951) have recorded responses from human spinal roots and dorsal spinal cord in their studies of the $\mathrm{H}$ wave. They concluded that the central delay was equivalent to that of one synapse and the response represented a monosynaptic reflex. This response can be facilitated and inhibited in the same manner as the monosynaptic reflex in the cat (Lloyd, 1946). These findings confirm the conclusions of Hoffmann (1918, 1922).

The unusual features of this response, which are described in the introduction, have not been adequately explained in the past and this study provides the following explanations of these salient points.

Although an $\mathrm{H}$ wave with the characteristics outlined above was recorded only in calf muscles in normal man, numerous investigators have reported the occurrence of $\mathrm{H}$ waves in other muscles of spastic patients (Magladery et al., 1952; Teasdall, Park, Languth, and Magladery, 1952; Languth, Teasdall, and Magladery, 1952) and in infants (Thomas and Lambert, 1960; Hodes and Gribetz, 1963; Blom, Hagbarth, and Skoglund, 1964). In this study we have observed this in patients with hemiplegia and in the spinal cat. Hagbarth (1962) and Liberson (1962) have reported that $\mathrm{H}$ waves can be recorded in small hand and foot muscles following facilitation by active contraction or tetanic stimulation. These observations suggest that the $\mathrm{H}$ wave needs facilitation to be recorded in normal resting muscle except in the triceps surae. This may best be explained by the anatomical arrangement of the triceps surae since here there are three large muscles which are direct heteronymous synergists. These muscles are supplied by a common nerve whose large afferents are superficial and may be stimulated by subthreshold shocks. A stimulus to their nerve would give rise to facilitation of their overlapping subliminal zones (Creed et al., 1932) and thus cause a large post-synaptic discharge, a heteronymous monosynaptic reflex discharge (Lloyd, Hunt, and McIntyre, 1955; Lloyd and McIntyre, 1955). This response is greatest when recorded from the surface of the lower calf because here the responses from the three muscles can be recorded as a large compound action poten- tial. The response recorded in individual resting muscles represents the homonymous monosynaptic discharge (Lloyd et al., 1955) and this is small and difficult to locate in normal man.

Hagbarth (1962) has reported that the response which was recorded at rest in the soleus was large 0 but appeared only with facilitation (active contraction) in the gastrocnemius. He concluded that the $H$ wave was best recorded in the soleus muscle and the gastrocnemius did not differ in this respect from other muscles of the extremity. The difference between these muscles was explained by the following facts: the soleus in cats gives a better stretch reflex than the gastrocnemius (Denny-Brown, 1929), motor neurones to the soleus (red) muscle have a greater excitatory post-synaptic potential than those to the gastrocnemius (pale) muscle (Eccles, Eccles, of and Lundberg, 1957), and slow postural muscles $\vec{\circ}$ as the soleus are more effectively excited by operation of the gamma loop (Granit, 1955). In our studies, $\vec{\omega}$ a large $\mathrm{H}$ wave could be recorded at rest in the gastrocnemius and soleus although not from every part of the former muscle. The response in the gastro- i cnemius has a different latency than that in the soleus and represents a separate response. This finding can probably be explained by the recerf observations of Romanul (1964) who found fibres 응 in localized parts of the gastrocnemius which have the same enzymatic patterns as the slow fibres in the soleus.

From the conduction velocities in the afferent and efferent fibres of this reflex, it can be concluded the large fibres (approximately 13 to $14 \mu$ ) are transmit ting the response. These afferent fibres are similar in size to those which Lloyd (1943b) studied in cats (12 to $20 \mu$ ) and classified as group I afferents. These fibres have been reported to conduct at rapid rates (72 to $120 \mathrm{~m}$./sec.) (Hunt, 1954). In our studies there was no significant difference between conduction in afferent and efferent fibres. The threshold to electrical stimulation should therefore be the same in these fibres. The difference in threshold between $\mathrm{H}$ and motor responses observed in the tibial nerve is probably due to the anatomical arrangement rather than different properties of the fibres. This arrangement of superficial layering of the large afferent $\exists$ fibres increases the ease of evoking the $\mathrm{H}$ reflex in the triceps surae.

The $\mathrm{H}$ wave can be blocked by a maximal stimulus for motor fibres. Lloyd (1943a) has reported that the maximal antidromic volley fails to block a reflex volley completely unless the opposed volleys clash in the motor axon. This is not possible unless the efferent impulse lags behind the afferent one by $N$ approximately 1 millisecond. From our studies in $\mathrm{N}$ man, impulses in the fastest afferent and efferent 
fibres should reach the spinal cord at approximately the same time. This has been demonstrated in the cat (Ekholm and Skoglund, 1964). Therefore, inhibition cannot occur in the motor axon. The inhibition of the $\mathrm{H}$ reflex, which is produced by an increase in stimulus intensity, may be due to excitation of higher threshold, slower conducting fibres to interneurones such as group II afferents which are inhibitory to motor neurones (Lloyd, 1946; Brooks and Eccles, 1948; Hunt, 1955). Another explanation for this inhibition may be related to the large number of refractory motor neurones produced by maximal antidromic impulses as reported by Renshaw (1941).

Following electric stimulation with single shocks at intervals of 1 to 20 seconds, the response amplitude of the $\mathrm{H}$ wave is variable and may be depressed for 20 seconds. As the rate of stimulation is increased, the variability ceases, the response amplitude is decreased, and the potential can be obliterated with rapid stimulation ( 5 to 6 per second). Therefore the frequency of stimulation must not exceed 1 per 30 seconds in any study which is performed to evaluate the amplitude of individual $\mathrm{H}$ responses.

This prominent variation in response amplitude to maximal or submaximal volleys is also a feature of the monosynaptic reflex response (Hunt, 1955). This indicates that motor neurones are subject to fluctuations in excitability and this in part may be due to variation in background activity of inter neurones. This in itself may be useful in the investigation of spinal cord dysfunction if the variability is studied quantitatively.

In patients with chronic polyneuropathy (nutritional or diabetic) the conduction velocity in the afferent fibres from the triceps surae is lower ( 50 to $60 \mathrm{~m}$./sec.) than normal $(80$ to $84 \mathrm{~m}$./ $/ \mathrm{sec}$.). This may be due either to complete blocking of large fibres with preservation of smaller, slower conducting fibres, or to slowing of fast conducting fibres. The amplitude of the $\mathrm{H}$ wave in these cases is small compared with normal and this suggests that there is a reduced efferent discharge.

Ascending nerve action potentials recorded in the tibial and peroneal nerves of these patients are small or absent (Mayer, 1963; Mawdsley and Mayer, 1964.) Conduction velocity in the fastest motor and sensory fibres in these nerves is also slow. These results are not transient and persist for months or years in individual cases. Histological studies of nerves performed in patients with chronic nutritional polyneuropathy have revealed that large fibres are affected more than small ones (Aring, Bean, Roseman, Rosenbaum, and Spies, 1941). Therefore in these patients with chronic polyneuropathy, the slow conduction velocities are the result of conduction in smaller fibres.

Observations of the $\mathrm{H}$ reflex during ischaemia of the tibial nerve reveal a slight increase in the latency ( 1.5 to $3 \mathrm{msec}$.) without change in amplitude initially. This change in conduction time is probably due to slowing of fast conducting fibres by ischaemia. With further ischaemia the large fibres are blocked first (Gasser, 1934) and the prolonged latency is due to conduction in smaller, slower conducting fibres. During and following spinal anaesthesia the latency of the $\mathrm{H}$ reflex is increased by approximately the same amount as observed during ischaemia and in patients with polyneuropathy. Therefore from these studies, it can be concluded that there are slower (small) conducting fibres which are part of the $\mathrm{H}$ reflex. These responses are not normally observed since they are included in the large $H$ potential. Fibres which conduct at rates of 50 to $60 \mathrm{~m}$./sec. are 8 to $10 \mu$ in diameter and are in the range of group II afferents (Lloyd, 1943b) which have polysynaptic connexions. The presence of fibres in the $\mathrm{H}$ reflex and ankle jerk which have polysynaptic connexions has been suggested previously in man (Teasdall et al., 1952; Magladery and Teasdall, 1958) and cat (Teasdall, Magladery, and Ramey, 1958) and receives support from this study.

The prolonged inhibition of the $\mathrm{H}$ wave following spinal anaesthesia is of interest since large fibres are usually the first to recover (Gasser and Erlanger, 1929). The depression of the ankle jerks during this same period may be due to fusimotor (small motor fibres) block and hence the rise in threshold of muscle spindle stretch receptors (Landau, Weaver, and Hornbein, 1960; Matthews and Rushworth, 1957 a, b). Since the $\mathrm{H}$ reflex bypasses the spindle, its inhibition is best explained by persistent blocking of some large fibres. Although Landau et al. (1960) previously reported that the $H$ wave was diminished at the same time when the ankle jerk was depressed during differential spinal block, they suggested that this resulted from fusimotor blockade, but the possibility remains likely that some of the large afferents for the $\mathrm{H}$ reflex were blocked at the same time as the gamma efferents.

The late response ( $F$ wave) recorded in small foot or hand muscles in normal man is similar to the $\mathrm{H}$ wave in the following ways. 1 The response depends on proximal conduction and is obliterated by spinal anaesthesia. 2 The response is facilitated by active contraction and following tetanic stimulation (Hagbarth, 1962), and 3,conduction in afferent and efferent fibres is the same (Dawson and Merton, 1956; Johns, Grob, and Harvey, 1957; Angel and Alston, 1964). The $F$ waves are not similar to $H$ waves in that the response is conducted in slower (smaller) 
fibres; threshold to electric stimulation is greater; the response is not blocked by maximal stimuli for motor fibres, and following spinal anaesthesia the $F$ wave returns at the same time as motor power and touch sensation and long before the $\mathrm{H}$ wave. The reflex response recorded in cat plantar muscles is obliterated by dorsal root section. If this can be considered the equivalent of the $F$ wave, this response is also reflex in origin. Magladery and McDougal (1950) concluded that the $F$ wave was reflex in origin with polysynaptic connexions and conduction was slower in afferent than efferent fibres. However, Dawson and Merton (1956) reported that conduction was the same in afferent and efferent fibres of the $F$ wave and concluded that the response resulted from a small recurrent discharge of a few motor neurones. This question cannot be definitely settled in man until the $F$ wave is studied during dorsal root blockade. Therefore, at the present time, this response should not be utilized in the investigation of peripheral nerve or spinal cord function.

The $\mathrm{H}$ reflex is clinically useful. It affords indices of conduction in fastest afferent fibres, of the number of motor neurones discharged, and of the activity of interneurones. If technical refinements of its elicitation are observed, then its alterations afford estimates of disturbed proximal conduction in peripheral neuropathies and altered motor neurone excitability in upper motor neurone lesions.

If the cat is to be used as an experimental model in further studies of the $\mathbf{H}$ reflex, great care must also be taken in the recording of the response. In this study chronic spinalization was necessary for regular recording of the $\mathrm{H}$ reflex in cats during pentobarbital anaesthesia. This agrees with the report of Teasdall et al. (1958) but differs from the study of Ekholm and Skoglund (1964). The response studied by the latter authors, however, was recorded through the skin and the latency of the potential was greater than that observed in our experiments. However, the latency of the $H$ wave $(6.5$ to $7.5 \mathrm{msec}$.), which we recorded in the gastrocnemius muscle of the cat, is similar to the latency of the tendon jerk recorded in the same muscle, 5.95 (Lloyd, 1943c) and $8.6 \mathrm{msec}$. (Denny-Brown, 1928). Since we have recorded a similar potential which is not reflex in origin, using surface electrodes on the calf, recordings should be made with concentric needles in muscle and the reflex nature of the response proved by proximal root section.

\section{SUMMARY}

In view of some recent differences in the interpretation of changes in the $\mathrm{H}$ wave, a systematic exploration of the fundamental characteristics of the phenomenon has been performed in man and in the cat and the following conclusions made. 1 The $\mathrm{H}$ wave recorded from calf muscles is reflex in origin and consists primarily of a monosynaptic linkage through large fibres but also contains a polysynaptic linkage through small fibres. 2 This response can be recorded in other muscles but facilitation is necessary. 3 Conduction velocities in the fastest afferent and efferent fibres of this reflex are the same and indicate that large fibres (13 to $14 \mu$ ) transmit the monosynaptic discharge. 4 In patients with peripheral neuropathies, the conduction velocity in these fibres is reduced and this is a useful test in the early diagnosis of peripheral nerve lesions. 5 The response amplitude and its variations may be used to measure motor neurone excitability provided that technical care is observed.

We wish to thank Professor D. Denny-Brown for his interest and advice during this study, and Drs. J. F. Ruscio, J. E. Lorenz, and W. V. McDermott Jr. for allowing us to study certain of their patients.

\section{REFERENCES}

Angel, R. W., and Alston, W. (1964). Spindle afferent conduction velocity. Neurology (Minneap.), 14, 647-676.

- , and Hoffmann, W. W. (1963). The $H$ reflex in normal, spastic, and rigid subjects. Arch. Neurol. (Chic.), 8, 591-596.

A ring, C. D., Bean, W. B., Roseman, E., Rosenbaum, N., and Spies, T. D. (1941). The peripheral nerves in cases of nutritional deficiency. Arch. Neurol. Psychiat. (Chic.), 45, 772-787.

Blom, S., Hagbarth, K. E., and Skoglund, S. (1964). Post-tetanic potentiation of H-reflexes in human infants. Exp. Neurol., $\leq$ 9, 198-211.

Brooks, C. McC., and Eccles, J. C. (1947). A study of the effects of anaesthesia and asphyxia on the mono-synaptic pathway through the spinal cord. J. Neurophysiol., 10, 349-360.

- - (1948). Inhibition of antidromic responses of motoneurones. Ibid., 11, 431-444.

Buller, A. J. (1957). The ankle-jerk in early hemiplegia. Lancet, 2, 1262-1263.

reflexes. Ibid., 2, 1260-1262.

Clare, M. H., and Landau, W. M. (1964). Fusimotor function. Part V. Reflex reinforcement under fusimotor block in normal subjects. Arch. Neurol. (Chic.), 10, 123-127.

Creed, R. S., Denny-Brown, D., Eccles, J. C., Liddell, E. G. T., and Sherrington, C. S. (1932). Reflex Activity of the Spinal Cord, pp. 84-103. Oxford University Press, London.

Dawson, G. D., and Merton, P. A. (1956). "Recurrent" discharges from motoneurones. $X X$ Int. Congr. Physiol., Brussels: Abstracts of Communications, pp. 221-222.

Denny-Brown, D. (1928). On inhibition as a reflex accompaniment of the tendon jerk and of other forms of active muscular response. Proc. roy. Soc. $B, 103$, 321-336.

- (1929). On the nature of postural reflexes. Ibid., 104, 252-301.

Eccles, J. C., Eccles, R. M., and Lundberg, A. (1957). The convergence of monosynaptic excitatory afferents on to many different species of alpha motoneurones. J. Physiol. (Lond.) 137, 22-50.

-_, and Sherrington, C. S. (1930). Numbers and contraction-values of individual motor-units examined in some muscles of the limb. Proc. roy. Soc. B, 106, 326-357.

Ekholm, J., and Skoglund, S. (1964). Possible factors influencing the demonstration of post-tetanic potentiation of the H-reflex as studied in the cat. Exp. Neurol., 9, 183-197.

Gassel, M. M., and Diamantopoulos, E. (1964a). The Jendrassik maneuver. I. The pattern of reinforcement of monosynaptic reflexes in normal subjects and patients with spasticity or rigidity. Neurology (Minneap.), 14, 555-560. 
Gassel, M. M., and Diamantopoulos, E. (1946b). The Jendrassik maneuver. II. An analysis of the mechanism. Ibid., 14, 640-642.

study of the pattern of conduction times in the distribution of the sciatic nerve. J. Neurol. Neurosurg. Psychiat., 27, 351-357.

Gasser, H. S. (1934). Conduction in nerves in relation to fiber types. Res. Publ. Ass. nerv. ment. Dis., 15, 35-59.

- and Erlanger, J. (1929). The rôle of fiber size in the establishment of a nerve block by pressure or cocaine. Amer. J. Physiol., 88, 581-591.

Granit, R. (1955). Receptors and Sensory Perception. Yale University Press, New Haven.

Hagbarth, K. E. (1962). Post-tetanic potentiation of myotatic reflexes in man. J. Neurol. Neurosurg. Psychiat., 25, 1-10.

Hodes, R., and Gribetz, J. (1963). Normal electrically induced reflexes ('H reflexes') in a 2-week-old infant with acrania and cerebral dysgenesis. Electroenceph. clin. Neurophysiol., 15, 1033-1036.

Hoffmann, P. (1918). Úber die Beziehungen der Sehnenreflexe zur willkürlichen Bewegung und zum Tonus. $Z$. Biol., 68, 351-370.

- (1922). Untersuchungen über die Eigenreflexe (Sehnenreflexe) menschlicher Muskelin. Springer, Berlin.

Hunt, C. C. (1954). Relation of function to diameter in afferent fibers of muscle nerves. J. gen. Physiol., 38, 117-131.

- (1955). Temporal fluctuation in excitability of spinal motoneurones and its influence on monosynaptic reflex response. Ibid., 38, 801-811.

Hursh, J. B. (1939). Conduction velocity and diameter of nerve fibers. Amer. J. Physiol., 127, 131-139.

Johns, R. J., Grob, D., and Harvey, A. M. (1957). An electromyographic study of a spinal cord reflex in the normal human arm. Bull. Johns Hopk. Hosp., 101, 232-239.

Landau, W. M., and Clare, M. H. (1964a). Fusimotor function. Part IV. Reinforcement of the $\mathrm{H}$ reflex in normal subjects. Arch. Neurol. (Chic.), 10, 117-122.

,$--(1964 b)$. Fusimotor function. Part VI. H reflex, tendon jerk, and reinforcement in hemiplegia. Ibid., 10, 128-134.

- Weaver, R. A., and Hornbein, T. F. (1960). Fusimotor nerve function in man. Differential nerve block studies in normal subjects and in spasticity and rigidity. Ibid., 3, 10-23.

Languth, H. W., Teasdall, R. D. and Magladery, J. W. (1952). Electrophysiological studies of reflex activity in patients with lesions of the nervous system. Bull. Johns Hopk. Hosp., 91, 257-266.

Liberson, W. T. (1962). Monosynaptic reflexes and their clinical significance. Electroenceph. clin. Neurophysiol., suppl. 22, pp. 79-89.

Lloyd, D. P. C. (1943a). The interaction of antidromic and orthodromic volleys in a segmental spinal motor nucleus. J. Neurophysiol., 6, 143-151.

- (1943b). Neuron patterns controlling transmission of ipsilateral hind limb reflexes in cat. Ibid., 6, 293-315.

- (1943c). Conduction and synaptic transmission of the reflex response to stretch in spinal cats. Ibid., 6, 317-326.

- (1946). Facilitation and inhibition of spinal motoneurones. Ibid., 9, 421-438.

11, 199-207.

- - Hunt, C. C., and McIntyre, A. K. (1955). Transmission in fractionated monosynaptic spinal refiex systems. J. gen. Physiol., 38, 307-317.

- - and McIntyre, A. K. (1955). Transmitter potentiality of homonymous and heteronymous monosynaptic reflex connections of individual motoneurons. Ibid., 38, 789-799.
Magladery, J. W., and McDougal, D. B. Jr. (1950). Electrophysiological studies of nerve and reflex activity in normal man. I. Identification of certain reflexes in the electromyogram and the conduction velocity of peripheral nerve fibres. Bull. Johns Hopk. Hosp., 86, 265-290.

$-\longrightarrow, \ldots$, and Stoll, J. (1950). Electrophysiological studies of nerve and reflex in normal man. II. The effects of peripheral ischemia. Ibid., 86, 291-312.

- -, Park, A. M., Porter, W. E., and Teasdall, R. D. (1952). Spinal reflex patterns in man. Res. Publ. Ass. nerv. ment. Dis., 30, 118-151.

_-, Porter, W. E., Park, A. M., and Teasdall, R. D. (1951). Electrophysiological studies of nerve and reflex activity in normal man. Bull. Johns Hopk. Hosp., 88, 499-548.

_- , and Teasdall, R. D. (1958). Stretch reflexes in patients with spinal cord lesions. Ibid., 103, 236-241.

- Park, A. M., and Languth, H. W. (1952). Electrophysiological studies of reflex activity in patients with lesions of the nervous system. Ibid., 91, 219-244.

Mark, R. F. (1963). Tonic stretch reflexes in the calf muscles of normal human subjects. Nature (Lond.), 199, 50-52.

Matthews, P. B. C., and Rushworth, G. (1957a), The selective effect of procaine on the stretch reflex and tendon jerk of soleus muscle when applied to its nerve. J. Physiol. (Lond.), 135, 245-262.

procaine. Ibid., 135, 263-269.

Mawdsley, C., and Mayer, R. F. (1965). Nerve conduction in alcoholic neuropathy. Brain, in the press.

Mayer, R. F. (1963). Nerve conduction studies in man. Neurology (Minneap.), 13, 1021-1030.

-

Paillard, J. (1959). Functional organization of afferent innervation of muscle studied in man by monosynaptic testing. Amer. J. phys. Med., 38, 239-247.

Ranson, S. W., Droegemueller, W. H., Davenport, H. K., and Fisher, C. (1934). Number, size and myelination of the sensory fibers in the cerebrospinal nerves. Res. Publ. Ass. nerv. ment. Dis., 15, 3-34.

Renshaw, B. (1941). Influence of discharge of motoneurons upon excitation of neighboring motoneurons. J. Neurophysiol., 4, 167-183.

Rexed, B. (1944), Contributions to the knowledge of the postnatal development of the peripheral nervous system in man. Acta psychiat., Neurol. (Stockh.) suppl. 33.

- and Therman, P. O. (1948). Calibre spectra of motor and sensory fibres to flexor and extensor muscles. J. Neurophysiol., 11, 133-139.

Romanul, F. C. A. (1964). Enzymes in muscle: I. Histochemical studies of enzymes in individual muscle fibers. Arch. Neurol. (Chic.), 11, 355-368.

Sommer, J. (1940). Periphere Bahnung von Muskeleigenreflexen als Wesen des Jandrassikschen Phänomens. Dtsch. Z. Nervenheilk., 150, 249-262.

Teasdall, R. D., Languth, H. W., and Magladery, J. W. (1952). Electrophysiological studies of reflex activity in patients with lesions of the nervous system. Bull. Johns Hopk. Hosp., 91, 267-275.

-, Magladery, J. W., and Ramey, E. H. (1958). Changes in reflex patterns following spinal cord hemisection in cats. Ibid., 103, 223-235.

_-, Park, A. M., Languth, H. W., and Magladery, J. W. (1952). Electrophysiological studies of reflex activity in patients with lesions of the nervous system. Ibid., 91, 245-256.

Thomas, J. E., and Lambert, E. H. (1960). Ulnar nerve conduction velocity and H-reflex in infants and children. J. appl. Physiol., $15,1-9$. 